\title{
Morphological and ultrastructural changes in Herpes simplex encephalomyelitis: an attempt to determinate the etiological factor
}

Teresa Wierzba-Bobrowicz ${ }^{1}$, Eliza Lewandowska ${ }^{1}$, Paulina Felczak ${ }^{1}$, Tomasz Stępień ${ }^{1}$, Albert Acewicz ${ }^{1}$, Sylwia Tarka ${ }^{1,2}$, Beata Błażejewska-Hyżorek ${ }^{3}$, Agnieszka Bednarska ${ }^{4}$, Ewa Matyja ${ }^{5}$, Wiesława Grajkowska ${ }^{6}$

${ }^{1}$ Department of Neuropathology, Institute of Psychiatry and Neurology, Warsaw, Poland, ${ }^{2}$ Departament of Forensic Medicine, Medical University of Warsaw, Poland, ${ }^{3}$ Second Department of Neurology, Institute of Psychiatry and Neurology, Warsaw, Poland, ${ }^{4}$ Department of Adult Infectious Diseases, Medical University of Warsaw, Warsaw, Poland, ${ }^{5}$ Department of Experimental and Clinical Neuropathology, Mossakowski Medical Research Centre, Polish Academy of Sciences, Warsaw, Poland, ${ }^{6}$ Department of Pathology, Children's Memorial Health Institute, Warsaw, Poland

\begin{abstract}
Herpes simplex encephalomyelitis (HSE) is a rare disease with a high mortality rate. Correct diagnosis is established on the basis of the combination of the clinical and investigative features. Unfortunately, precise diagnosis remains difficult due to several clinical similarities and false negative or inconclusive results of diagnostic tests. Here, we present two cases of HSE together with the morphological and ultrastructural picture. The first case was a 45-year-old man with acute symptoms of encephalitis, and the other one was a 28-year-old woman presenting subacute encephalomyelitis. Both cases had negative serologic and molecular results for Herpes simplex in the blood and cerebrospinal fluid. Brain and spinal cord samples taken from both cases were stained typically with histological and immunohistochemical methods and small tissue fragments were examined with the transmission electron microscope (TEM). Microscopic examination confirmed viral encephalomyelitis in both cases. An electron micrograph showed typical intranuclear viral particles inside of damaged neurons, which together with topography of brain and spinal cord changes suggest HHV-1/HHV-2 in the first case and/or HHV-3 in the other case. Thus, morphological and ultrastructural examinations may be a useful tool to set up correct diagnosis and help to determine the pathogenic factor in patients suspected of viral encephalomyelitis.
\end{abstract}

Key words: encephalomyelitis, ultrastructure, microscopic, herpes simplex.

\section{Introduction}

Herpes simplex encephalitis/encephalomyelitis (HSE) is a rare disease that is estimated to occur in 2-5 individuals per million population per year but remains the most common form of mortal encepha- litis worldwide $[8,21]$. In the absence of treatment, HSE has an extremely high fatality rate at about $70 \%$ with fewer than $3 \%$ of survivors returning to normal life $[7,9,25]$. Despite treatment, the associated fatality rate is still high (about 30\%) and permanent disability is common $[4,11]$.

\section{Communicating author}

Teresa Wierzba-Bobrowicz, Department of Neuropathology, Institute of Psychiatry and Neurology, 9 Sobieskiego St., 02-957 Warsaw,

Warsaw, Poland, e-mail: bobrow@ipin.edu.pl 
The human herpes virus family includes 8 viruses: HHV-1 (human herpes virus-1; previously herpes simplex virus-1, HSV-1, herpes labialis), HHV-2 (previously herpes simplex-2, HSV-2, herpes genitalis), HHV-3 (previously varicella zoster virus/chickenpox, VZV), HHV-4 (Epstein-Barr virus, EBV), HHV-5 (cytomegalovirus, CMV), HHV-6A, HHV-6B and HHV-7 and HHV-8 (or Kaposi's sarcoma-associated herpes virus). They all consist of a large (125-235 kb), linear, double-stranded DNA genome enclosed within an icosahedral capsid [21]. More than $80 \%$ of the HSE cases are caused by HHV-1, the others by HHV-2, HHV-3, HHV-4 and HHV-5.

A special feature of human herpes viruses are the property of latent survival in the infected human body (latent phase) and the possibility of periodic reactivation. Before establishing the latent phase, places for replicates of HHV-1, HHV-2 and HHV-3 are trigeminal and lumbosacral ganglia. Brain and/or spinal cord infection are thought to occur by means of direct neuronal transmission of the virus from a peripheral site (in the lytic phase) after reactivation. The virus enters the brain via the trigeminal or olfactory nerve, the spinal cord, respectively via vertebral and spinal nerves [14]. The viruses cause haemorrhagic necrosis and inflammatory infiltrates $[12,13]$. The pathway of entry of the virus determines the type of damage structure in the brain and the level of damage to the spinal cord $[2,19,27]$.

The diagnosis of herpes simplex encephalitis/ encephalomyelitis is established on the basis of the combination of the clinical and investigative features. Unfortunately, precise diagnosis still remains difficult due to several similarities to other neurological disorders (i.e. non-HSE encephalitis, brain tumour) and false negative results of serological and/or molecular tests $[2,5,6]$. The occurrence following herpes simplex encephalitis is probably more common than is generally recognized [7]. In our study we would like to present two HSE encephalitis cases together with the morphological and ultrastructural picture. Thus, in unclear cases, the morphological and ultrastructural examination may be crucial to set up the correct diagnosis.

\section{Material and methods}

\section{Case 1}

A 45-year-old patient with a clinical history of ulcerative colitis treated with immunosuppressive drugs was admitted to our hospital because of disturbances of the state of consciousness, right-sided paresis and aphasia, which progressed over a few days. He had no fever, meningeal irritation and other systemic physical examination abnormalities. Brain magnetic resonance imaging (MRI) demonstrated hyperintense signal in the left temporal lobe corresponding to oedematous changes probably in the course of tumour. Cerebrospinal fluid (CSF) analysis showed a mild increase in the protein level with no pleocytosis. In the next few days, the general and neurological condition worsened to coma, right-sided paralysis and respiratory failure. An urgent neurosurgical resection of the left temporal lobe and part of the hippocampus was performed. After the operation, the condition improved: the patient was conscious, fulfilling simple commands, respiratory and circulatory efficient with right-sided paresis and aphasia. Control MRI showed post-operative haemorrhagic lesions in the left temporal lobe and T2- and FLAIR-hyperintense signal symmetrically in the deep structures of both hemispheres, brainstem and medial cortex of the left parietal and temporal lobe (Fig. 1). Neuropathological examination excluded the tumour and raised a suspicion of inflammatory lesions. Further diagnostics and treatment took place in the infectious hospital. CSF flow cytometry analysis, blood and CSF bacterial and fungi cultures, HHVs polymerase chain reaction ( $P C R)$ tests were negative. Hospitalization was complicated by massive pulmonary embolism and epileptic seizures. However after several months the patient was discharged with a significant general and neurologic improvement.

\section{Case 2}

A 28-year-old woman with a history of chronic rhinosinusitis was admitted to our hospital because of severe thoracic pain, numbness and weakness in the lower extremities, which occurred after returning from a 2-week trip to the Romanian Carpathians. Before the trip she felt headaches and a slight tingling of the left lower limb. Her initial neurological examination revealed decreased sensation at the level Th4-5 and at the right lower limb, which in a few hours progressed to right lower limb paresis with sensory loss to all modalities below Th3. Spine MRI revealed a T2- and FLAIR-hyperintensity in the spinal cord from C6 to Th6 and brain MRI in the left medial frontal gyrus and left parietal lobe. CSF analysis revealed mild 
pleocytosis $(68$ cells $/ \mu l)$ and increased protein level $(23.5 \mathrm{mg} / \mathrm{dl})$. CSF flow cytometry analysis results were negative. Blood and CSF serological and PCR tests (HHV, CMV, VZV, EBV, toxoplasmosis, borreliosis), bacterial and fungi cultures were negative. The patient's general and neurological condition rapidly deteriorated despite intensive treatment (methylprednisolone, acyclovir, ceftriaxone); in the next few days, symptoms of increased intracranial pressure, hemiparesis and respiratory failure appeared - an external ventricular drainage was performed with transient clinical improvement. The patient died of sudden cardiac arrest on the 11th day of hospitalization.

\section{Methods}

Brain samples obtained from the temporal lobe resection of the first patient and post-mortem brain and spinal cord samples from the second patient were fixed in $10 \%$ buffered formalin and embedded in paraffin. The specimens were stained with haematoxylin-eosin, Bielschowsky and PAS methods. Immunohistochemical studies were performed with antibodies to GFAP (DAKO 1 : 70), CD68 (CellMarque 1 : 250), CD20 (Novocastra 1 : 10), CD4545RO (Leica 1 : 500), LCA (DAKO 1 : 75). For electron microscope evaluation, small fragments of brains were taken from formalin or paraffin blocks. After deparaffinizing and/or washing in water, the material was fixed in $2.5 \%$ glutaraldehyde and post fixed in $2 \% \mathrm{OsO} 4$, then routinely processed to Spurr resin. Ultrathin sections were stained with uranyl acetate and lead citrate. The sections were examined and photographed with transmission electron microscope (TEM) JEOL model 1400.

\section{Results}

Light microscopic examination of the brain samples taken from the first patient revealed necrotic and haemorrhagic lesions, with both grey and white matter parenchymal infiltration composed of lymphocytes and macrophages/microglial cells (Figs. 2, 3C, D). Perivascular cuffing of inflammatory cells, mainly lymphocytes T, macrophages and plasma cells were also observed (Figs. 2A, B, D, 3D). Around necrosis proliferation of the reactive astrocytes with plain cytoplasm were found (Fig. 3A, B). Sometimes lymphocytes and microglia formed nodules and microglial cells appeared like rod cells (Fig. 2B). Electron micrograph showed typical intranuclear viral particles inside of damaged of neurons (Fig. 4).

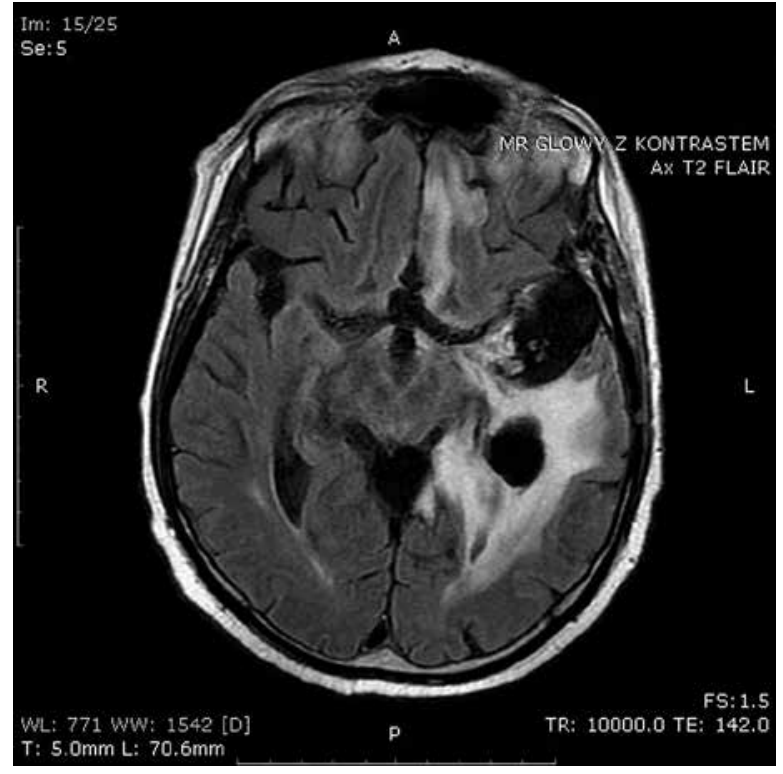

Fig. 1. Postoperative brain MRI of the first case. Hyperintensity on FLAIR T2-weighted imaging in the left temporal lobe and in the deep structure of both brain hemispheres.

In the other case, brain and spinal cord gross examination showed generalized brain swelling, necrotic and haemorrhagic lesions in the left medial frontal gyrus and parietal lobe and destruction of the thoracic spinal cord. Microscopic examination revealed lesions of haemorrhage and necrosis with parenchymal infiltration of lymphocytes and macrophages/microglial cells (Fig. 5). Microgliosis was predominantly diffuse. Near the necrosis, reactive astroglia were visible (Fig. 5). Additionally, foci of axonal damage were noted (Fig. 6B). Spinal cord destruction was present from the $\mathrm{C} 6$ to Th6 level with predominance in the posterior corners (Fig. 6A). Electron microscopic examination showed viral capsids distributed in the neurons (Fig. 7). Nuclei of neurons often displayed a wavy membrane contour and expanded perinuclear space, whereas chromatin mostly a fine granular pattern (Fig. 7A).

\section{Discussion}

In our present study we showed two cases of viral encephalomyelitis with diagnosis based on the morphological and ultrastructural examination of the brain tissue and spinal cord. In the first case, acute course suggested brain tumour, therefore a neurosurgical operation was performed. Exclusion of the tumour in the neuropathological examination 

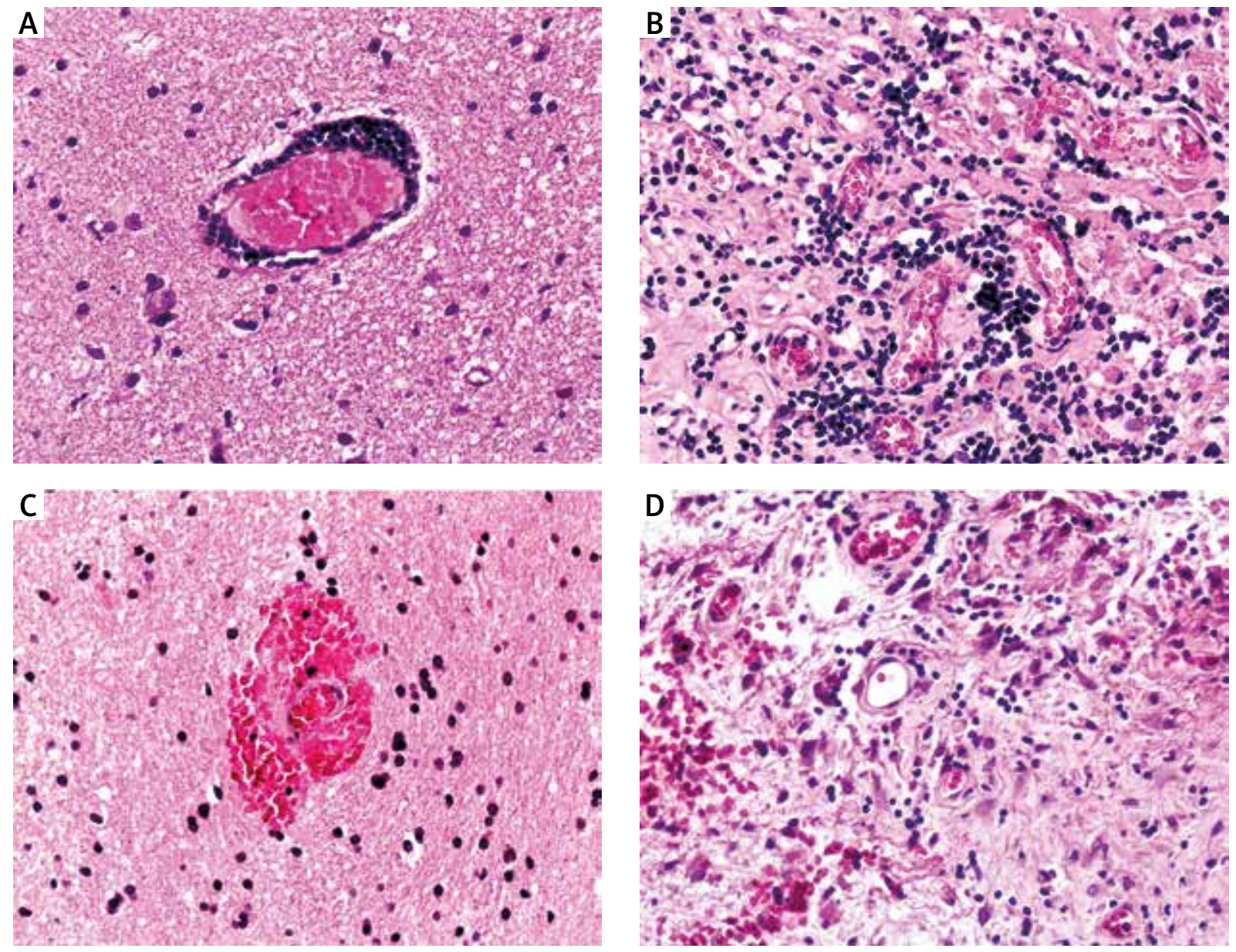

Fig. 2. Microscopic changes in the left temporal lobe of the first case. A) Perivascular inflammatory infiltration (HE, 20x); B) Proliferation of lymphocytic and microglial cells (HE, 20x); C) Erythrocytic perivascular cuffing (HE, 20x); D) Necrotic and haemorrhagic lesions (HE 10x).

of the resected brain tissue enabled the implementation of effective (anti-viral) treatment. In the other case with subacute clinical course, extraventricular drainage was implemented to decrease intracranial pressure. According to the literature, decompressive craniectomy or external ventricular drainage seems to be the effective treatment for cerebral oedema or increased intracranial pressure due to infectious encephalitis $[1,3,17,20]$. Correct diagnosis of HSE still remains challenging, which in relation to frequent rapid course results in consistently high mortality. Several symptoms may occur due to damage of various brain or spinal cord regions, brain/spinal cord oedema or increased intracranial pressure, i.e. headache, nausea/vomiting, alteration of consciousness, aphasia, hemiparesis/paraparesis, seizures, vision impairment, and sensory disturbances. How- ever no symptom is pathognomonic for HSE and may appear in the course of other neurological disorders, i.e. brain abscess, tumour, limbic encephalitis, and stroke $[10,15,16,22]$. Typically CT scans and MRI in HSE, showed an area of hyperintense, FLAIR and hyperintense T1 signal, affecting both frontal lobes, temporal lobes and insula. Foci of haemorrhage can be observed occasionally $[18,20]$. In the first case, abnormal findings in MRI involved deep brain structures of both hemispheres of the brain, medial cortex of the left parietal lobe and the left temporal lobe. This localisation may be related to the route of entry of the virus (HHV-1, HHV-2) into the brain via cranial nerves. In the other case, the localisation of the morphological changes may be related to the entry of the virus (HHV-1, HHV-2 and/or HHV-3) into brain and spinal cord via vertebral nerves $[2,22]$. Serologic 

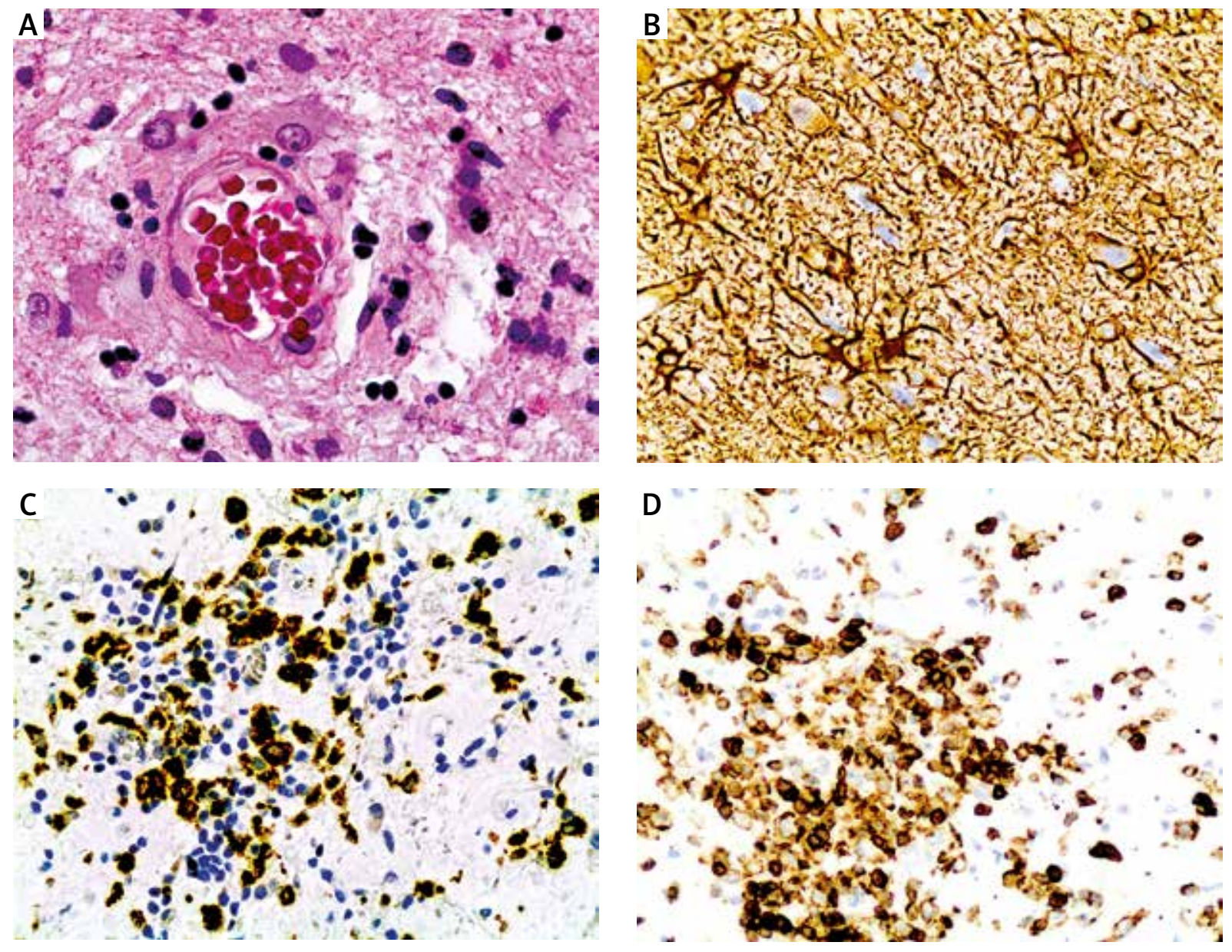

Fig. 3. Microscopic changes in the left temporal lobe of the first case. A) Proliferation of reactive astroglia and rod-like microglia (HE, 40x); B) Proliferation of astroglia (GFAP, 20x); C) Macrophages and microglial cells in necrotic lesions (CD68, 20x); D) Lymphocyte T infiltration (CD45RO, 20x).

evaluation of blood or CSF may be useful for diagnosis, however it has no role in patients with the acute clinical course and for fast therapeutic decisions. CSF analysis results are frequently inconclusive and may show mild pleocytosis or remain normal. Therefore, confirmation of the diagnosis usually depends on the identification of HHV in the CSF by means of a PCR or on the identification of HHV in brain tissue by means of brain biopsy. Rarely PCR results may be misleading, due to false negative results. In both our cases, the presence of virus HHV DNA in CSF has not been confirmed by PCR. Thus, ultrastructural examination remains the only investigation, which allows to set up correct diagnosis [24,25].

According to Wild et al., HHV capsids are assembled in the nucleus at the inner nuclear membrane into the perinuclear space [26]. After de-enveloped

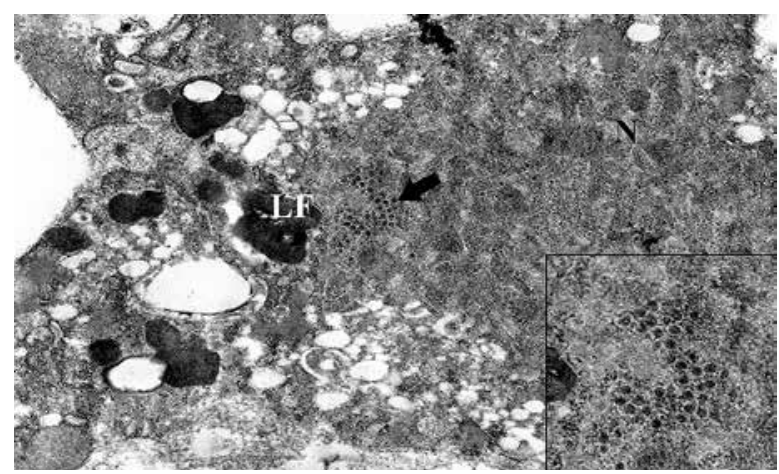

Fig. 4. Ultrastructural changes in the degenerated neuron of the first case. The osmophilic lipofuscin deposits (LF) and numerous vacuoles are present in the cytoplasm. Viral nucleocapsid (black arrow) in the form of dark granular deposits surrounded by a light hallo are visible in the concentrated nucleoplasm (N) (7000x, insert 12000x). 

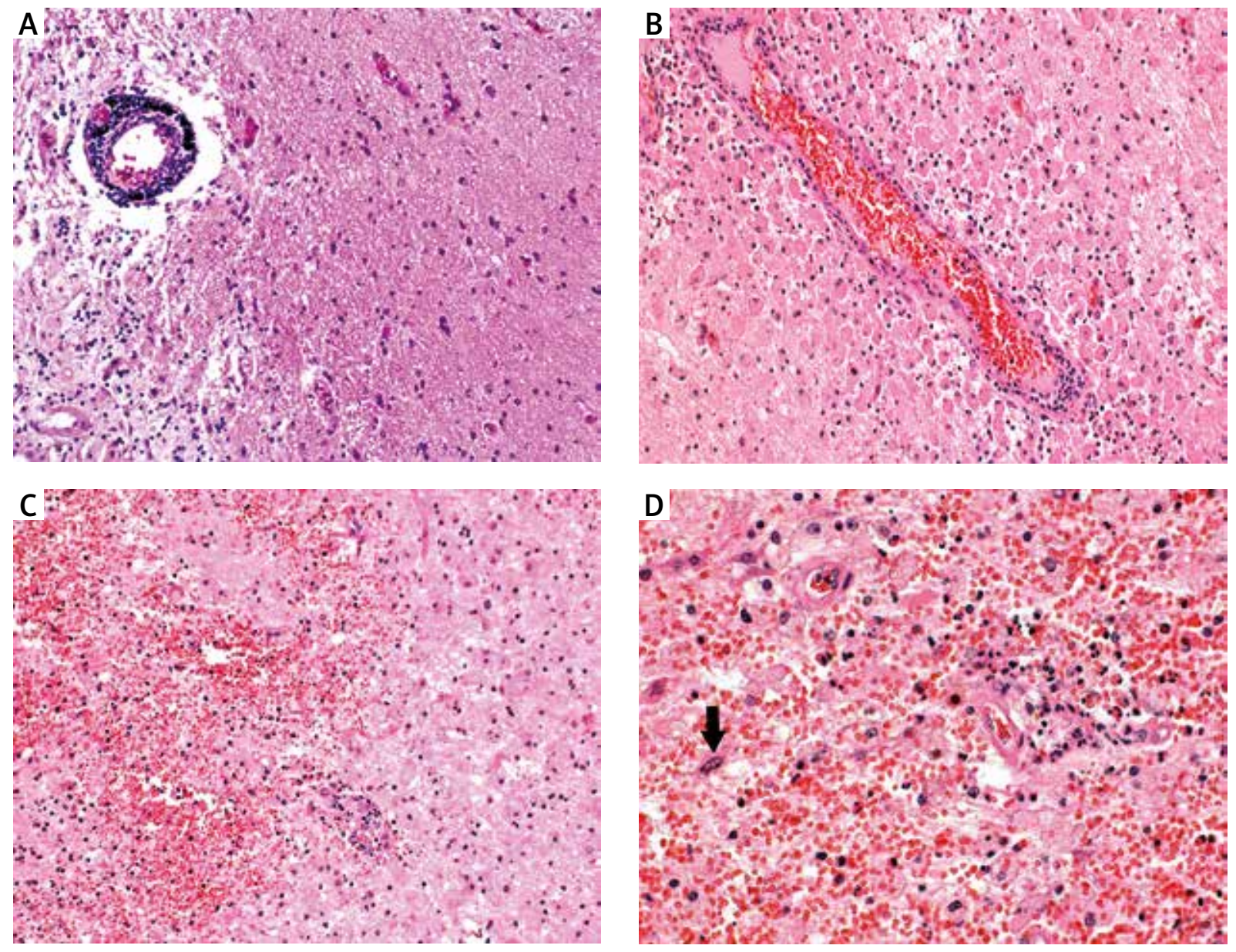

Fig. 5. Microscopic changes in the left frontal and parietal lobe of the second case. A) Perivascular inflammatory cells in the left frontal lobe (HE, 10x); B) Necrosis with proliferation of macrophages in the left frontal lobe $(\mathrm{HE}, 20 \mathrm{x})$; C) Necrosis with haemorrhage and lymphocytes and macrophages/microglia infiltration in the left parietal lobe (HE, 10x); D) Necrosis with haemorrhage, macrophages and reactive astroglia (arrow) in the left parietal love (HE, 40x).
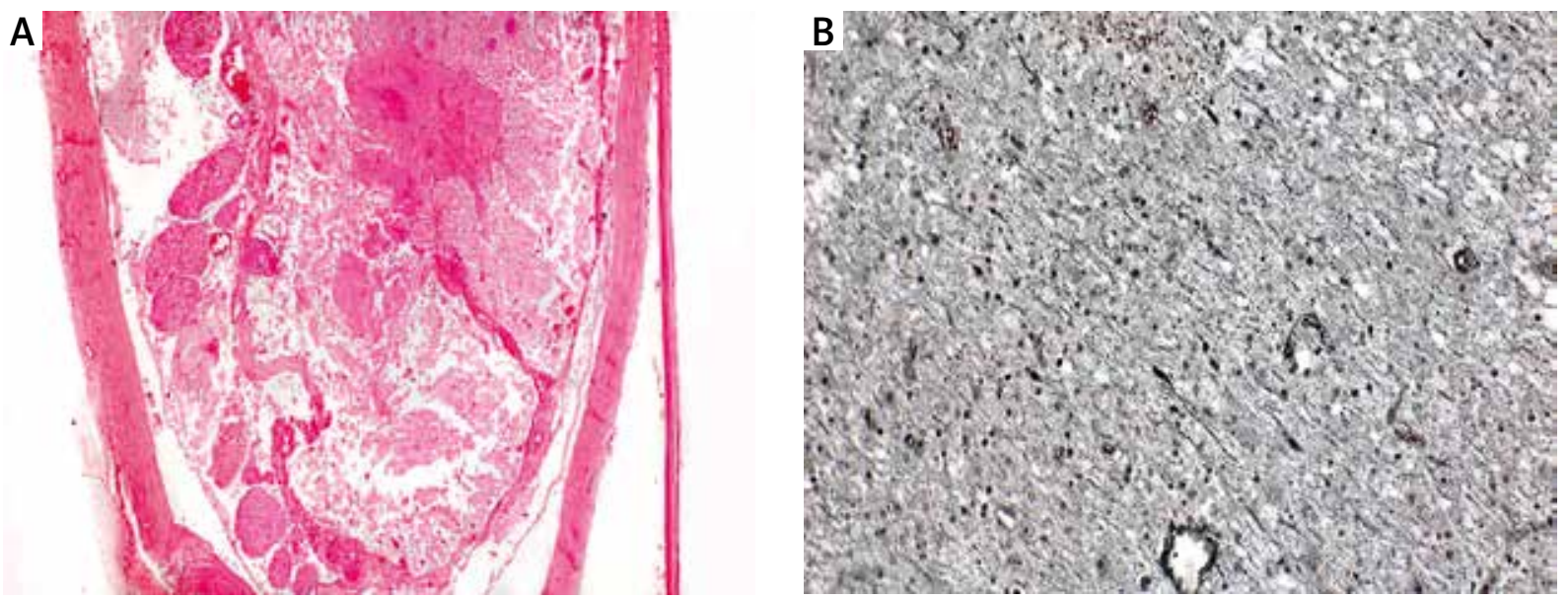

Fig. 6. Microscopic changes in the thoracic spinal cord and left frontal lobe of the second case. A) Necrosis of the spinal cord (HE, 5×); B) Axonal damage of the left frontal lobe (Bielschowsky, 10x). 

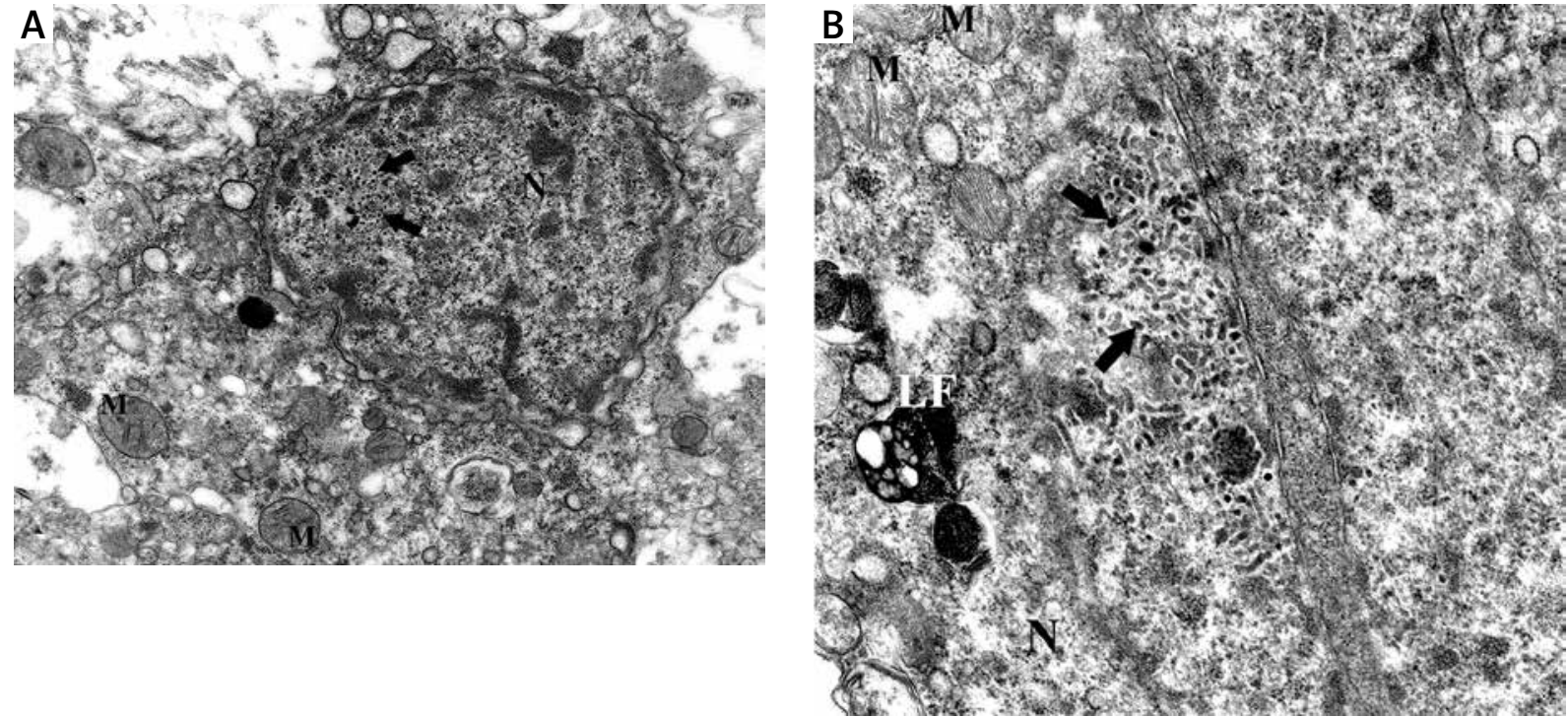

Fig. 7. Ultrastructural changes in the degenerated neuron of the second case. A) Wavy nuclear membrane contour and expanded perinuclear space are visible. Numerous viral capsids in the form of dark grains surrounded by a light hallo (arrows) forming a fine granular pattern located in the nucleus (N). Mitochondria (M) (7000x), B) Numerous viral capsids (arrows) are distributed in the nucleus of neuron (N). Lipofuscin (LF), mitochondria (M) (12000x).

and re-enveloped in Golgi membranes, virions become infectious. Ultrastructural pictures of capsids in the nucleus indicated HHV-1, HHV-2 or HHV-3 [24,26].

\section{Conclusions}

Morphological and ultrastructural examinations in patients suspected of viral encephalomyelitis may be a useful tool to set up correct diagnosis, help to determine the pathogenic factor and assess the effectiveness of treatment. Decompressive craniectomy or external ventricular drainage could be regarded as a rescue treatment in cases with signs of brain oedema or increased intracranial pressure due to infectious encephalitis.

\section{Acknowledgements}

The material was derived from the First Polish Brain Bank in the Institute of Psychiatry and Neurology, Warsaw, Poland. This work is supported by the "Digital Brain - digital collection of the Institute of Psychiatry and Neurology" (Project No. POPC.02.03.0100.0042/18-00). The authors are very grateful to the First Polish Brain Bank in the Institute of Psychiatry and Neurology, Warsaw, Poland.

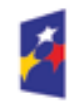

European

Funds

Oigitad Poland

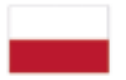

Republic European Union of Poland

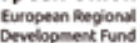

\section{Disclosure}

The authors report no conflicts of interes.

\section{References}

1. Adamo MA, Deshaies EM. Emergency decompressive craniectomy for fulminating infectious encephalitis. J Neurosurg 2008; 108: 174-176.

2. Bubak AN, Como CN, Blackmon AM, Jones D, Nagel MA. Varicella zoster virus differentially alerts morphology and suppresses proinflammatory cytokines in primary human spinal cord and hippocampal astrocytes. J Neuroinflamm 2018; 15: 318-327.

3. Bustos RB, Vigueras SA, Pinto JV. Craniectomia decomprenciva en encephalitis herpética. Caso clinico. Revista Chilena de Pediatria 2012; 83: 468-473.

4. Chan PK, Chow PC, Peiris JS, Mak AW, Huen KF. Use of oral valaciclovir in a 12-year-old boy with herpes simplex encephalitis. Hong Kong Med J 2000; 6: 119-121.

5. De Tena GJ, de Pablo Sánchez R, Daguerre Talou M, López Matamala B, Martínez Díaz C. The value of polymerase chain reaction in cerebrospinal fluid for the diagnosis of herpetic encephalitis; report of 2 cases and a review of the literature. An Med Interna 2000; 17: 81-83.

6. Dorcet G, Benaiteau M, Bost C, Mengelle C, Bonneville F, Martin-Blondel G, Pariente J. Two cases of late-onset anti-NMDAr auto-immune encephalitis after herpes simplex virus 1 encephalitis. Front Neurol 2020; 11: 38.

7. Greenwood R, Bhalla A, Gordon A, Roberts J. Behaviour disturbances during recovery from herpes simplex encephalitis. J Neurol Neurosurg Psychiatry 1983; 46: 809-817. 
8. Hjalmarsson A, Blomqvist P, Sköldenberg B. Herpex simplex encephalitis in Sweden, 1990-2001: incidence, morbidity, and mortality. Clin Infect Dis 2007; 45: 875-880.

9. Itzhaki RF. Corroboration of a major role for herpes simplex virus type 1 in Alzheimer's disease. Front Aging Neurosci 2018; 10: 324.

10. Jay V, Becker LE, Otsubo H, Cortez M, Hwang P, Hoffman HJ, Zielenska M. Chronic encephalitis and epilepsy (Rasmunssen's encephalitis). Neurology 1995; 45: 108-117.

11. Jouan Y, Grammatico-Guillon L, Espitalier F, Cazals X, François P, Guillon A. Long-term outcome of severe herpes simplex encephalitis: a population-based observational study. Crit Care 2015; 19: 345-354.

12. Kennedy PGE, Chaundhuri A. Herpes simplex encephalitis. J Neurol Neurosurg Psychiatry 2002; 73: 237-238.

13. Kennedy PGE, Quan PL, Lipkin WI. Viral encephalitis of unknown cause: current perspective and recent advances. Viruses 2017; 9: 138.

14. Maertzdorf J, Van der Lelij A, Baarsma GS, Osterhaus AD, Verjans GM. Herpes simplex virus type 1 (HSV-1) induced retinitis following herpes simplex encephalitis: indications for brainto-eye transmission of HSV-1. Ann Neurol 2000; 48: 936-939.

15. Martins HM, Teixeira-Jr AL, Lana-Peixoto MA. Acute hemorrhagic leukoencephalitis mimicking herpes simplex encephalitis. Arq Neuropsiquiatr 2004; 62: 139-143.

16. McJunkin JE, de los Reyes EC, Irazuzta JE, Caceres MJ, Khan RR, Minnich LL, Fu KD, Lovett GD, Tsai T, Thompson A. La crosse encephalitis in children. N Engl J Med 2001; 11: 801-807.

17. McLaughlin DC, Achey RL, Geertman R, Grossman J. Herpex simplex reactivation following neurosurgery: case report and review of the literature. Neurosurg Focus 2019; 47: E9.

18. Nguyen I, Urbanczyk K, Mtui E, Li S. Intracranial CNS infections: a literature review and radiology case studies. Semin Ultrasound CT MR 2020; 41: 106-120.

19. Parra M, Alcala A, Amoros C, Baeza A, Galiana A, Tarragó D, Garcia-Quesada MA, Sánchez-Hellin V. Encephalitis associated with human herpesvirus-7 infection in an immunocompetent aduld. Virol J 2017; 14: 97-102.

20. Peres-Bovet J, Garcia-Armengol R, Buxo-Pujolras M, Lorite-Diaz N, Narvaez-Martinez Y, Caro-Cardera JL, Rimbau-Munoz J, Joly-Torta MC, Castellvi-Joan M, Martin-Ferrer S. Decompresive craniectomy for encephalitis with brain herniation: case report and review of literature. Acta Neurochir 2012; 154: 1717-1724.

21. Popiel M, Wietrak E, Laskus T. Opryszczkowe zapalenie mózgu. Pos Mikrobiol 2012; 51: 185-190.

22. Simon K, Dziemianko I. Obraz kliniczny zakażeń herpensviridae w stanach obniżonej odporności - u chorych po przeszczepach szpiku kostnego i narządów miąższowych. Przegląd Epidemiologiczny 2003; 58: 289-297.

23. Sköldenberg B. Herpes simplex encephalitis. Scand J Infect Dis Suppl 1996; 100: 8-13.

24. Skuja S, Zieda A, Ravina K, Chapenko S, Roga S, Teteris O, Groma V, Murovska M. Structural and ultrasrtuctural alterations in human olfactory pathways and possible associations with herpesvirus 6 infection. PLoS One 2017; 12: e.0170071.

25. van Sonderen A, Thijs RD, Coenders EC, Jiskoor LC, Sanchez E, de Bruin MAAM, van Coevorden-Hameete MH, Wirtz PW,
Schreurs MWJ, Sillevis-Smitt PAE, Tirulaer MJ. Anti-LGI 1 encephalitis. Clinical syndrome and long-term follow-up. Am Acad Neurol 2016; 87: 1443-1456.

26. Wild P, Leisinger S, de Oliveira AP, Schraner EM, Kaech A, Ackermann M, Tobler K. Herpes simplex virus 1 Us3 deletion mutant is infective despite impaired capsid translocation to the cytoplasm. Viruses 2015; 7: 52-71.

27. Yoshimoto G, Mori Y, Kato K, Shima T, Miyawaki K, Kikushige Y, Kamezaki K, Numata A, Maeda T, Takenaka K, Iwasaki H, Teshima T, Akashi K, Miyamoto T. Human herpes virus-6-associated encephalitis/myelitis mimicking calcineurin inhibitor-induced pain syndrome in allogeneic stem cell transplantation recipients. Biol Blood Marrow Transplant 2018; 24: 2540-2548. 